\section{PERCEPÇÃO ESTUDANTIL SOBRE O ENSINO-APRENDIZAGEM DE CONCEITOS TERMOQUÍMICOS COM PRÁTICAS LÚDICAS}

\section{STUDENT PERCEPTION ABOUT \\ TEACHING-LEARNING THERMOCHEMICAL CONCEPTS WITH LUDIC PRACTICES}

Carmen de Assunção Neves ${ }^{1, *} /$ Robson Júnior dos Santos Costa ${ }^{1} /$ Sílvia Cláudia Marques Lima ${ }^{1}$

\section{INTRODUÇÃO}

No atual contexto tecnológico, nota-se a preferência docente por ferramentas da tecnologia, mediante seus usos ao serviço do desenvolvimento da ludicidade no âmbito escolar. Essas novas estratégias visam despertar o interesse dos alunos, de modo a conciliar teoria e prática, primando pelos estímulos do universo digital. Tais inovações permitem aos professores criar possibilidades lúdicas em detrimento de modelos pré-formatados, para que os docentes se construam sujeitos capazes de expor, ouvir, pesquisar, avaliar, dar voz e renovar o seu processo pedagógico (CABRAL, 2015, p. 8).

No entanto, mesmo sob tal cenário, o modo da instrução das ciências, em especial da Química, possui ainda caráter tradicional, sobretudo no ensino da Termoquímica, ao se referir à peculiaridade do modo de ensinar de cada docente. Ao impor tais métodos, os docentes transferem aos alunos o temor e a desmotivação, por esse modo de ensino não se conectar ao cotidiano discente. Por certo, tal forma causalhes resistência à teoria por seu carácter abstrato, e isso os faz considerá-la de difícil compreensão por desconhecerem a finalidade de estudá-la e aprendê-la (PESSOA; ALVES, 2015).

Muitas vezes, essa problemática de correlacionar a teoria dos processos Termoquímicos com a sua prática possui estreita sintonia com a ausência de utilização de recursos lúdicos que possibilite experiências de percepção discente sobre a importância de tal estudo da Química.

\section{RESUMO}

Esta pesquisa analisa a efetividade de ações lúdicas como estratégia pedagógica na aprendizagem de conceitos termoquímicos abordados no componente Química, sob a percepção discente, em turmas do $2 .^{\circ}$ ano do Ensino Médio dos Colégios Estaduais de Guanambi-BA. Neste enfoque, utilizaram-se os métodos de abordagem quali-quantitativa, subsidiados pelo instrumento questionário estruturado fechado, cujas abordagens contemplaram uma amostra de 72 alunos na qual corresponde a $20 \%$ dos 361 estudantes destes Colégios. Os resultados apontam a necessidade da presença lúdica na compreensão dos conceitos termoquímicos abordados em Química, cujas estratégias fortalecem habilidades cognitivas, além de ressignificarem os métodos de ensino. Todavia, se faz necessário haver o caráter da aula tradicional dada sua funcionalidade. Esta requer atualização para a nova sociedade tecnológica, posto que, as motivações e as estratégias lúdicas aprimoram sentidos e o interesse discente para uma consequente aprendizagem.

Palavras-chave: Conceituação. Ludicidade. Química. Estratégias pedagógicas.

\section{ABSTRACT}

This research analyzes the effectiveness of playful actions as a pedagogical strategy in the learning of thermochemical concepts covered in the Chemistry component, under the student's perception, in second year classes at the State Schools of Guanambi-BA. Under this focus, the methods of qualitative and quantitative approach were used, subsidized by the closed structured questionnaire instrument, whose approaches contemplated a sample of 72 students in which corresponds to $20 \%$ of the 361 students from these Colleges. The results point to the need for a playful presence in understanding the thermochemical concepts addressed in Chemistry, whose strategies strengthen cognitive skills, in addition to giving new meaning to teaching methods. However, it is necessary to have the character of the traditional class given its functionality, it requires updating to the new technological society, since, the motivations and playful strategies improve meanings and the student's interest for a consequent learning.

Keywords: Conceptualization. Playfulness. Chemistry. Pedagogical strategies.

Submetido em: 2 de mai. 2020

Aceito em: 11 de dez. 2020

${ }^{1}$ Instituto Federal de Educação, Ciência e Tecnologia Baiano - IF Baiano,

Guanambi, Bahia - Brasil

*E-mail para correspondência: carmenassuncao22@gmail.com

Rev. ComCiência - dez. 2020, vol. 5, no. 7, p. 22-27/ doi: 10.36112/issn2595-1890.v5.i7.p22-27 
Nesse cenário de estímulos, há diversas propostas metodológicas que emergem no processo de ensino e aprendizagem voltadas ao desenvolvimento de atividades, com uso da ludicidade, tais como: jogos educacionais, brincadeiras, experimentos e paródias musicais, os quais não só constituem propostas prazerosas ao aprendizado, como também propiciam a interação dos estudantes, por meio de trabalhos em grupos e interações afetivas (MEDEIROS, 2016).

No entanto, Cunha (2012) sentencia que há em sala de aula muitas pesquisas e experiências lúdicas que carecerem de referencial teórico capaz de as sustentar. Mesmo que muitos professores utilizem os termos "motivação, aprendizagem e interesses" em trabalhos, de maneira espontânea, quase nunca os definem ou os apoiam por referenciais teóricos consistentes. Para a autora, o campo do lúdico no ensino de Química ainda se centra em um processo pedagógico de "ativismo".

Esse ativismo está relacionado na seguinte situação: quando se pensa em jogos e atividades lúdicas na área de Ensino de Química, envolvendo conceitos termoquímicos, de imediato se imagina elaborar jogos, ainda que sem clareza dos princípios norteadores de tais atividades. Esses trabalhos se baseiam em "intuição" contributiva de aprendizado do aluno, por meio de jogos elaborados. Porém, não pode somente com essa percepção constatar se há ou não aprendizagem dos conceitos trabalhados pelo discente, em determinados jogos, posto que tal comprovação implica superar o senso comum. Assim, "precisamos mostrar em nossas discussões, como o jogo de fato auxiliou na apreensão do conceito pretendido" (SOARES, 2016, p. 12). Evidencia-se, desse modo, que sem a teoria explícita e consciente, a prática a envolver o lúdico subverte em espontaneísmo e, com isso, não se explora o potencial dos jogos com adequação devida, em sala de aula.

Essa lacuna no ensino impõe-se a necessidade de que em escolas estaduais do município de Guanambi haja ações voltadas à estratégia pedagógica de conceitos termoquímicos do componente Química, à aprendizagem. Nessa perspectiva, sempre quando se questiona aos docentes sobre o que mais causa dificuldade na aplicação de alternativas lúdicas, a maior parte indaga a insuficiência de carga-horária para aulas práticas, considerado este fato um bloqueio maior para o processo de assimilação. Assim como:

Para a aprendizagem efetiva, mister se faz contextualizar e associar teoria à prática, e o emprego dos conceitos Químicos, de modo que não haja aulas expositivas e memorísticas. Assim, faz-se relevante preparar professores, ampliar discussões de ensino, melhorar métodos e técnicas adotados e, fomentar a busca por inovações pela ressignificação dos conceitos Químicos (TRINDADE; LIMA, 2015, p. 5).

Tais necessidades de melhorias elevam-se, entretanto, quando se refere a escolas da região Nordeste do Brasil, pois se acredita que a realidade nestas instâncias do conhecimento, em especial na Bahia, em escolas estaduais de Guanambi, lócus dessa pesquisa, Território Sertão Produtivo, prescindem-se de estudos aprofundados acerca das formas atuais de aprendizagem, especificamente no que concerne aos conceitos termoquímicos.

Sob tal premissa, este estudo se fez social e educacionalmente relevante por contribuir com aprofundamentos teóricos e resultados, sob a percepção dos estudantes acerca de possibilidades pedagógico-lúdicas nestas escolas. Além disso, buscou-se especificidades do saber Químico direcionado à razão cognitiva e ao aprendizado no uso de estratégias lúdicas de conceitos termoquímicos. Assim, constata-se salutar diante do nível de importância para a região, lócus desta pesquisa, diagnosticar realidades e/ou melhorias, no olhar discente, em função do real uso da ludicidade e das possibilidades de intervenções contempladas com uso dessas ferramentas para as atividades específicas supracitadas desse ensino, uma vez que o estudo das Ciências, na qual engloba a Química e os conceitos termoquímicos, quando embasados exclusivamente de forma livresca, sem interação direta com os fenômenos naturais ou tecnológicos, deixa enorme lacuna na formação dos estudantes. Desse modo, faz-se necessário o emprego de diferentes métodos ativos, com a utilização de observações, experimentação, jogos, diferentes fontes textuais para obter e comparar informações que despertem o interesse dos estudantes pelos conteúdos e conferem sentidos à natureza e à ciência que não são possíveis ao se estudar Ciências Naturais apenas em um livro (BRASIL, 1998, p. 27).

Nesse sentido, sob a curiosidade investigativa, indagou-se: há efetividade à aprendizagem, na estratégia pedagógica de conceitos termoquímicos do componente Química? Diante desse questionamento, coube analisar a efetividade de ações lúdicas como estratégia pedagógica na aprendizagem de conceitos termoquímicos do componente Química, sob a percepção discente, em turmas do 2..$^{\circ}$ ano do Curso Formação Geral dos Colégios Estaduais: Idalice Nunes e Modelo Luís Eduardo Magalhães, na cidade de Guanambi, estado da Bahia. 
Para tanto, fez-se mister investigar a existência de atividades pedagógico-lúdicas no ensinoaprendizagem de conceitos termoquímicos em Química, na percepção de estudantes das escolas supracitadas; analisar a contribuição de recursos estrutural-pedagógicos à realização de ações lúdicas no ensino de conceitos da termoquímica; averiguar o estímulo à aprendizagem de ações interdisciplinares inter-relacionadas à ludicidade no componente química nas escolasalvo; analisar a existência de motivação com ações lúdicas para a aprendizagem quando contextualizadas a conteúdos inter-relacionados ao cotidiano nas escolas-alvo da pesquisa, sob o olhar dos estudantes; atestar resultados da efetividade estratégia lúdica para os conceitos termoquímicos no ensino do componente Química, de acordo com a percepção estudantil de $2 .^{\circ}$ ano.

\section{MATERIAIS E MÉTODOS}

Para o alcance dos objetivos desta pesquisa, utilizaram-se os métodos qualitativo e quantitativo, alicerçados pelo instrumento questionário estruturado fechado, visto se tratar de técnica pertinente quando empregada a problemas cujos objetos de pesquisa correspondem a questões de caráter empírico, mas que envolvem opinião, percepção e posicionamento dos pesquisados, por se tratar de um processo de abordagem investigativa, de cunho descritivo-exploratório. De acordo com Dal Farra e Lopes (2013, p. 1) "a conjugação de elementos qualitativos e quantitativos possibilita ampliar e obter resultados em abordagens investigativas, proporcionando ganhos relevantes às pesquisas complexas realizadas no campo da Educação". Sendo assim, podem minimizar as dificulda- des nas práticas produzindo dessa forma resultados relevantes.

Para maior abordagem a respeito do objeto de estudo: efetividade de ações lúdicas como estratégia pedagógica na aprendizagem de conceitos termoquímicos no componente Química, sob a percepção discente, no $2 .^{\circ}$ ano do Ensino Médio, utilizou-se as áreas de estudos dos Colégios Estaduais: Idalice Nunes e Modelo Luís Eduardo Magalhães. Estas instituições de ensino localizam-se na cidade de Guanambi-BA, município pertencente ao Território Sertão Produtivo, no Sudoeste baiano, a aproximadamente 790 km da capital Salvador-Bahia, conforme o Instituto Brasileiro de Geografia e Estatística (IBGE, 2017). O público da amostra contemplou 72 alunos de um total de 361 alunos, ou seja $20 \%$ dos estudantes do $2 .^{\circ}$ ano dos dois colégios estaduais. Destes, entrevistaram-se 303 estudantes cujos 20\% totalizam 61 alunos, pertencentes ao Colégio Estadual Modelo, comportados nas 9 turmas. E 11 alunos que correspondem a $20 \%$ de 58 estudantes do Colégio Idalice Nunes, número pertencente a 2 salas de $2 .^{\circ}$ ano, no turno vespertino, entre os dias 13 a 16 de novembro de 2018.

Após a coleta de dados, e, mediante os objetivos deste estudo, construíram-se resultados que foram, a seguir, compilados e tabulados, firmados na ética, equidade e qualidade da investigação científica.

\section{ANÁLISES E DISCUSSÃo DE RESULTADOS}

Mediante as dificuldades dos discentes à compreensão do conteúdo dos conceitos termoquímicos abordados no componente Química, pode-se afirmar que o uso de métodos lúdicos como estratégia à melhoria do ensino- aprendizagem se torna imprescindível aos professores. Para a concretização desta afirmativa, conforme já comentado, a utilização do questionário, como instrumento investigativo, sucedeu indispensável à análise de percepção dos discentes, havendo como principal foco a eficácia das atividades lúdicas no processo de ensinoaprendizagem nos conceitos termoquímicos de Química. Buscou-se nas questões objetivas: investigar a existência de atividades pedagógicolúdicas, analisar a contribuição de recursos estrutural-pedagógicos para a realização destas atividades, averiguar o estímulo para a aprendizagem com ações interdisciplinares e verificar se há motivação nestas ações lúdicas.

Porto (2015) assegura relevante para o professor, que tenha ou aprenda a ter uma "postura lúdica" no ambiente escolar, de modo a fornecer inúmeros benefícios à aprendizagem dos seus alunos, para possibilitar o desenvolvimento da inteligência emocional, da motivação, do senso crítico e da capacidade autoavaliava, além do estímulo à criatividade, à socialização, e ao raciocínio lógico.

Assim sendo, no que se refere a recursos representativos da termoquímica, tais como explanação de imagens e vídeos que relatem os processos endotérmicos e exotérmicos - absorção e liberação de calor, respectivamente, à aplicação de atividades lúdicas, na sala de aula, dos 72 alunos entrevistados, $44.5 \%$, ou seja, 32 alunos declararam tais ações. E destas modalidades, as mais utilizadas voltam-se àquelas baseadas na análise de dados. Vê-se, no entanto, que apesar de ser um número considerável de estudantes, que representa a sua metade expressiva, acredita-se que há muito ainda a ser feito nesse sentido. Almeida, I., Almeida, V. e Sousa (2017) 
destacam a necessidade do planejamento das atividades lúdicas no processo educativo, com objetivos e metodologias definidos, dando suporte para averiguar a ação do educador, em relação ao desenvolvimento e à aprendizagem. No entanto, 25 alunos, ou seja, 35\% dos estudantes afirmaram que não há atividades dessa natureza nas aulas de Química.

De acordo com a Tabela 1, $33 \%$, ou seja, 24 alunos apontaram que o recurso pedagógico de maior contribuição para o aprendizado de conceitos da termoquímica consistiu-se na aula prática sobre estados físicos da matéria com modelo cinético molecular. Para Pinto (2012), por meio da realização de práticas experimentais, torna-se possível oportunizar ao aluno, tanto do Ensino Médio quanto do Superior, conhecer a essência da Química, descobrir sua importância e a estreita relação desta ciência com a natureza circundante. Nesse sentido, perceberam-se que tais experimentos oportunizam ao estudante familiarizar-se com o processo científico, ao adquirir uma compreensão desmistificadora do 'fazer ciência'. Segundo Rushton, Lotter e Singer (2011), além de despertar o interesse dos alunos, as aulas experimentais proporcionam também maior e melhor divulgação da ciência, ao salientar seu aspecto positivo, e, desse modo, o aluno vivencia na prática a execução dos processos termoquímicos. Acerca do método da Explanação de vídeos sobre diferenças entre calor e temperatura, 21 alunos optaram pela escolha deste como o recurso que mais contribuiu à aprendizagem dos conceitos termoquímicos.

Nessa ótica, a concretude da prática fortalece a assimilação do conteúdo. Desse modo, ao analisar as estruturas presentes na realização de atividades criativas no estudo da ter- moquímica, 61\% (44) alunos responderam que os laboratórios representam infraestrutura que mais coopera para a aprendizagem. De fato, envolver os alunos na realização de trabalho laboratorial instiga o valor a suas potencialidades, por lhes permitir desenvolver capacidades que implicam não só aprender o conhecimento conceitual e experimental, como também a aprendizagem de metodologia científica e a promoção de capacidades de pensamento (SANTOS; MALDANER; 2010).

Tabela 1 - Recursos mais eficazes à aprendizagem de conceitos termoquímicos, em ordem crescente de escolhas discentes

\begin{tabular}{|l|c|c|}
\hline Recursos & $\begin{array}{c}\text { Ordem crescen- } \\
\text { te do favoreci- } \\
\text { mento à apren- } \\
\text { dizagem de } \\
\text { conceitos } \\
\text { termoquímicos }\end{array}$ & Total \\
\hline $\begin{array}{l}\text { Aula prática sobre } \\
\text { estados físicos da matéria } \\
\text { com modelo cinético } \\
\text { molecular. }\end{array}$ & 24 & 72 \\
\hline $\begin{array}{l}\text { Explanação de vídeos } \\
\text { sobre diferenças entre } \\
\text { calor e temperatura. }\end{array}$ & 21 & 72 \\
\hline $\begin{array}{l}\text { Questionários e/ou } \\
\text { pesquisas sobre situaç̃̃es } \\
\text { cotidianas dos estudantes } \\
\text { mediadas pelo(a) } \\
\text { professor(a). }\end{array}$ & 13 & 72 \\
\hline Feiras de Ciências. & 6 & 72 \\
\hline $\begin{array}{l}\text { Exposição de imagens de } \\
\text { fenômenos físicos e } \\
\text { químicos. }\end{array}$ & 6 & 72 \\
\hline Sem resposta & 2 & 72 \\
\hline
\end{tabular}

Fonte: Acervo da pesquisa

Visando averiguar o estímulo para a aprendizagem com ações interdisciplinares inter-relacionadas a outras disciplinas, com 32\%, ou seja, 23 alunos evidenciam que ocorrem integradas às disciplinas de Física, Biologia e Matemática. Mas, ainda assim, 26,4\% (19) alunos constatam que não ocorrem atividades de integração.

Diante disso, após analisar o estímulo à aprendizagem com ações interdisciplinares inter-relacionadas à ludicidade no componente química nas escolas-alvo, verifica-se que aproximadamente $46 \%$, ou seja, 33 alunos atestam que as aulas laboratoriais são ações voltadas ao seu cotidiano, nas quais aplicadas pelos docentes os estimulam para estudos da termoquímica e os fazem aprender, uma vez que compreendem e enfatizam a capacidade de relacionar o conteúdo abordado a outras matérias.

Nesse aspecto, a expressividade de escolha das atividades lúdicas voltadas à termoquímica baseou-se acerca de 73,5\%, 53 alunos, nas quais afirmam que se sentem mais motivados a aprender quando inter-relacionada ao seu cotidiano pelos usos de experimentos. Segundo Silva (2016), a Química presente no cotidiano constitui importante porque promove a interconexão entre o conhecimento prévio do aluno e o científico. Vale salientar que a construção do saber científico implica discussões, observações, dentre outros meios, possibilitando também maior interação entre os alunos, ao motivá-los a buscar razões e explicações para os fenômenos que os rodeiam.

Quando abordados sobre quais experiências têm despertado motivação para aprender conceitos termoquímicos, a dinâmica em grupo utilizando situações-problema compreende-se em $39 \%$, sob a percepção de 28 discentes, seguido por $36 \%$ que compreende 26 alunos.

$\mathrm{Na}$ pretensão de se averiguar o estímulo para a aprendizagem, 32\% (23) alunos constatam-se que aulas expositivas com a utilização de recursos audiovisuais modernos que despertem o interesse dos estudantes e $32 \%$ (23) alunos também acreditam que intervenções em laboratório e pesquisas sobre processos atrelados aos conceitos da termoquímica podem se tornar o conteúdo da termoquímica mais atrativo para possibilitar um melhor aprendizado.

Nesse contexto, corrobora a estratégia pedagógica que mais facilita o 
uso da ludicidade para uma melhor aprendizagem da termoquímica. $\mathrm{Na}$ análise de 40,3\% (29) alunos, necessitam-se de uma melhor infraestrutura física e de materiais do colégio, bem como os laboratórios capacitados para a execução de experimentos relacionados aos conceitos termoquímicos, entretanto, 23 alunos dos quais representam $32 \%$, consideram que trabalhos de pesquisas que envolvem aprofundamento do assunto em debates provocadores de questionamentos, relacionados aos conceitos sobre os diferentes resultados e opiniões obtidos entre os grupos, mais os facilitam.

Ao analisar a Tabela 2, constatou-se que $32 \%$ (23) estudantes afirmam que estabelecem novas formas interativas e dinâmicas de apreensão do conhecimento, constitui-se de uma tática que dispõe em um maior grau à eficácia das ações lúdicas para uma aprendizagem significativa dos conceitos termoquímicos. Quanto a isso, Silva (2017) afirmam que o sujeito, por meio do lúdico, adquire múltiplas possibilidades de aprendizagem com desenvolvimento pleno, visto que ele atua com conteúdos do cotidiano, como interações com o meio e com objetos, além da diversidade de linguagens envolvidas em sua prática.

\section{CONSIDERAÇÕES FINAIS}

As atividades lúdicas fazem-se cada vez mais presentes na sala de aula do 2. ${ }^{\circ}$ ano do Ensino Médio de química, e em especial nos conceitos da termoquímica. Foram evidenciados, após dados tabulados que a maioria dos estudantes compreende que tais atividades são relevantes, visto que os envolvem, motivem e despertem o interesse pelo conteúdo de Termoquímica, posto tornarem as aulas dinâmicas e interessantes. No entanto, ainda assim, é expressivo o número de estudantes que afirmam não haver atividades dessa natureza nas salas de aulas. Deste modo, faz-se relevante constatar que, mesmo trabalhando nas salas de aulas alternativas lúdicas, muitos ainda não compreendem o seu real motivo, enfatizando assim a extrema importância de adaptar às práticas lúdicas associadas ao conteúdo trabalhado, ou seja, é necessário basear a prática em referenciais teóricos consistentes, que fundamentem as atividades lúdicas realizadas.

Diante disso, é necessário constatar que os alunos avaliam de forma positiva as atividades lúdicas desenvolvidas para os conceitos termoquímicos em turmas de $2 .^{\circ}$ ano, sendo assim favoráveis à aquisição e/ou fortalecimento de habilidades cognitivas, além da ressignificação dos conteúdos inter-relacionadas a outras matérias.

Tabela 2 - Escolhas discentes de objetivos para a aprendizagem significativa de conceitos termoquímicos, em ordem crescente de eficácia

\begin{tabular}{|l|c|c|}
\hline \multicolumn{1}{|c|}{ Objetivos } & $\begin{array}{c}\text { Escolhas } \\
\text { discentes em } \\
\text { ordem } \\
\text { crescente }\end{array}$ & $\begin{array}{c}\text { Total } \\
\text { de alunos(as) } \\
\text { entrevista- } \\
\text { dos(as) }\end{array}$ \\
\hline $\begin{array}{l}\text { Estabelecer novas formas } \\
\text { interativas e dinâmicas de } \\
\text { apreensão do conheci- } \\
\text { mento. }\end{array}$ & 23 & 72 \\
\hline $\begin{array}{l}\text { Permitir aos alunos } \\
\text { analisar os problemas, as } \\
\text { situações es aconteci- } \\
\text { mentos, dentro de um } \\
\text { contexto e em sua } \\
\text { globalidade. }\end{array}$ & 22 & 72 \\
\hline $\begin{array}{l}\text { Desenvolver a habilidade } \\
\text { de resolução de proble- } \\
\text { mas. }\end{array}$ & 18 & 72 \\
\hline $\begin{array}{l}\text { Favorecer a apropriação } \\
\text { de conceitos para atender } \\
\text { as características da } \\
\text { adolescência. }\end{array}$ & 7 & 72 \\
\hline $\begin{array}{l}\text { Ampliar a rede de } \\
\text { significados construtivos } \\
\text { em todas as idades. }\end{array}$ & 2 & 72 \\
\hline \begin{tabular}{l} 
Sem resposta \\
\hline
\end{tabular} & 0 & 72 \\
\hline Fonte. Acervo pesquisa & & \\
\hline
\end{tabular}

Fonte: Acervo da pesquisa

A utilização de atividades lúdicas no ensino conecta-se à busca por melhorias no processo de ensino e aprendizagem, sendo imprescindível adaptar-se a mudanças e às constantes evoluções tecnológicas pós-modernas.

\section{REFERÊNCIAS}

ALMEIDA, Irene Rodrigues de; ALMEIDA, Valdirene Rodrigues de; SOUSA, Claudia de Oliveira de. O papel da ludicidade na educação infantil na perspectiva de professora de uma escola pública do interior do estado de Mato Grosso. Revista Eletrônica da Faculdade de Alta Floresta, Mato Grosso, v. 6, n. 2, p. 58-73, 2017.

BRASIL. Ministério da Educação. Secretaria de Educação Fundamental. Parâmetros curriculares nacionais: terceiro e quarto ciclos do ensino fundamental: ciências naturais. Brasília, DF: MEC/SEF, 1998. Disponível em: http://portal.mec.gov.br/seb/arquivos/p df/ciencias.pdf. Acesso em: 17 nov. 2018.

CABRAL, Zuleica Aparecida. Ser professor na cultura digital: e agora? Artefactum: Revista de Estudos em Linguagem e Tecnologia, Rio de Janeiro, v. 11, n. 2, 2015.

CUNHA, Marcia Borin da. Jogos no ensino de Química: considerações teóricas para sua utilização em sala de aula. Química Nova na Escola, São Paulo, v. 34, n. 2, p. 92-98, maio 2012.

DAL-FARRA, Rossano André; LOPES, Paulo Tadeu Campos. Métodos mistos de pesquisa em educação: pressupostos teóricos. Nuances: Estudos sobre Educação, São Paulo, v. 24, n. 3, 2013. Disponível em:

http://revista.fct.unesp.br/index.php/N uances/article/view/2698/2362. Acesso em: 18 nov. 2018.

IBGE. Principais informações sobre o município de Guanambi. 2017. Disponível em: https://www.ibge.gov.br/busca.html?se archword=GUANAMBI\&searchphrase= all Acesso em: 17 nov. 2018.

MEDEIROS, Claudia Escalante. Uma proposta para o ensino de Química em busca da superação dos obstáculos epistemológicos. 2014. 157 f. Dissertação (Mestrado em Ensino de Ci- 
ências e Matemática) - Programa de Pós-Graduação em Ensino de Ciências e Matemática, Faculdade de Educação, Universidade Federal de Pelotas, Pelotas, 2014.

PESSOA, Wilton Rabelo; ALVES, José Moysés. Motivação para estudar química: configurações subjetivas de uma estudante do segundo ano do ensino médio. Interacções, v. 11, n. 39, p. 589-601, 2015.

PINTO, Angelo C. O ensino médio de química: o que fazer para melhorá-lo? Journal of the Brazilian Chemical Society, v. 23, n. 6, p. 985-986, 2012.

PORTO, Maria das Graças Cleophas. Jogo, TIC e ensino de química: uma proposta pedagógica. Recife: UFRPE, 2015. 249 f. Tese (Doutorado em Ensino de Ciências) - Programa de PósGraduação em Ensino das Ciências, Universidade Federal Rural de Pernambuco, Recife, 2015.

RUSHTON, Gregory T.; LOTTER, Christine; SINGER, Jonathan. Chemistry teachers' emerging expertise in inquiry teaching: the effect of a professional development model on beliefs and practice. Journal of Science

Teacher Education, v. 22, n. 1, p. 2352, 2011.

SANTOS, Wildson Luiz Pereira dos; MALDANER, Otávio Aloisio (Orgs). Ensino de Química em Foco. Ijuí: Unijuí, 2010. 368 p.

SILVA, Gerson Pindaíbs da. A educação infantil na contemporaneidade.

Revista Científica Multidisciplinar

Núcleo do Conhecimento, ano 2,. v. 1, p 527-539, abr. 2017.

SILVA, Vinícius Gomes da. A importância da experimentação no ensino de química e ciências. 2016. Trabalho de Conclusão de Curso (Graduação em Licenciatura em Química) - Faculdade de Ciências, Universidade Estadual Paulista, Bauru, 2016.

SOARES, Márlon Hebert Flora Barbosa. Jogos e atividades lúdicas no ensino de Química. 2004. 203f. Tese (Doutorado em Química) - Universidade Federal de São Carlos, São Carlos, SP, 2004.

TRINDADE, Simeia Barbosa; LIMA, Sílvia Cláudia Marques. Estrutura didático-pedagógica e capacitação docente em química no ensino médio dos colégios estaduais inseridos no Pibid, Guanambi-BA. 2015.Trabalho de Conclusão de Curso (Graduação em Licenciatura em Química ) - Instituto Federal de Educação, Ciência e Tecnologia Baiano, Campus Guanambi, 2015. 